\section{Onset and Duration Period of Pulpal Anesthesia of Articaine and Lidocaine in Inferior Alveolar Nerve Block}

Isabel Peixoto Tortamano ${ }^{1}$, Marcelo Siviero², Sara Lee ${ }^{1}$, Roberta Moura

Sampaio ${ }^{1}$, Jose Leonardo Simone ${ }^{1}$, Rodney Garcia Rocha ${ }^{1}$
'Department of Stomatology, School of Dentistry, USP - University of São Paulo, São Paulo, SP, Brazil ${ }^{2}$ Department of Stomatology, School of Dentistry, UPF - University of Passo Fundo, Passo Fundo, MG, Brazil

Correspondence: lsabel Peixoto Tortamano, Avenida Professor Lineu Prestes, 2227, Cidade Universitária, 05508-000 São Paulo, SP, Brasil. Tel/Fax: +5511-3091-7893/3091-7913/30917815. email: iptortam@usp.br

\begin{abstract}
The purpose of this prospective, randomized, double blind study was to compare the onset and duration periods of pulpal anesthesia using 2\% lidocaine with 1:100,000 epinephrine, 4\% articaine with 1:100,000 epinephrine and 4\% articaine with 1:200,000 epinephrine in inferior alveolar nerve block (IANB). Thirty subjects received $1.8 \mathrm{~mL}$ of each of the three local anesthetic solutions in IANB. Onset and duration periods of pulpal anesthesia were determined using electric pulp stimulation. The mean time of onset of pulpal anesthesia was 8.7, 7.4 and 7.7 min and the mean duration of pulpal anesthesia was $61.8,106.6$ and 88.0 min for $2 \%$ lidocaine with 1:100,000 epinephrine, 4\% articaine with 1:100,000 epinephrine and 4\% articaine with 1:200,000 epinephrine, respectively. For onset, there was only a significant difference between $2 \%$ lidocaine with 1:100,000 epinephrine and $4 \%$ articaine with 1:100,000 epinephrine $(p=0.037)$. For duration, there was significant difference for all the local anesthetic solutions ( $p \leq 0.05)$. In conclusion, $4 \%$ articaine with 1:100,000 epinephrine exhibited faster onset and also had longest duration of pulpal anesthesia in IANB.
\end{abstract}

Key Words: articaine, epinephrine, inferior alveolar nerve block, lidocaine, local anesthetics.

\section{Introduction}

Although it has been speculated that articaine has a faster onset and higher success rates than lidocaine (1) in response to a letter to the editor in JADA 2000 by Schertzer (2), with the exception of four studies done on the mandibular (3-6) and two on the maxilla $(7,8)$, most clinical studies have not been able to confirm that such superiority in fact occurs (9-17).

A recently concluded meta-analysis, comparing efficacy and safety of articaine with lidocaine in dental treatment, states that articaine is a better anesthetic than lidocaine for dental procedures. The same research also highlighted the lack of studies related to anesthesia onset, to confirm that articaine has faster onset of action than lidocaine, as observed in clinics (18).

Meechan (19) has contributed with interesting comments on this meta-analysis (18), stating that the infiltration or block techniques were not considered individually. Therefore, it is not possible to affirm whether $4 \%$ articaine is more effective than $2 \%$ lidocaine in mandibular block, and such an important question remains unanswered.

Another recent meta-analysis (20) comparing pulpal anesthetic efficacy between articaine and lidocaine in dentistry, claimed that the superiority of articaine is more significant when used during local anesthesia infiltration. However, there is little evidence that articaine use allows a high anesthetic success rate when administered via mandibular block. Therefore, the results regarding articaine success in mandibular block are inconclusive (20) and few studies have evaluated the impact of the concentration of the vasoconstrictor contained in the articaine solutions $(21,22)$.

The purpose of this study was to compare the onset and duration periods of pulpal anesthesia after IANB using 2\% lidocaine with 1:100,000 epinephrine, 4\% articaine with 1:100,000 epinephrine and 4\% articaine with 1:200,000 epinephrine.

\section{Material and Methods}

The Ethics Committee for Human Research at the School of Dentistry of the University of São Paulo approved this prospective, randomized, double-blinded clinical study (Protocol \#152/01). The guidelines from the Helsinki Declaration were followed and each subject gave written informed consent to participate in the study.

Thirty adult subjects, 15 women and 15 men $(n=30)$, ranging in age from 18 to 40 years old, with a mean of 24.63 years, presenting at least three vital asymptomatic mandibular posterior molars, diagnosed with occlusal caries in enamel, without restoration, pulpal calcification and periodontal disease (which were clinically and radiographically confirmed), were selected at the Emergency Center of the School of Dentistry at the University of São Paulo. These subjects also exhibited healthy contralateral canine teeth, i.e., without presence of 
deep cavities, extensive restorations, periodontal disease, and no history of trauma or sensitivity. To be included in the study, the subjects had to be between 18 and 40 years old in good health as established according to a health history questionnaire. Patients who took medication potentially interacting any of the anesthetics used in the study were not included.

The 30 blinded subjects randomly received an IAN block injection of either of solutions: LID0100 - 2\% lidocaine with 1:100,000 epinephrine (Alphacaine 100; DFL, Rio de Janeiro, RJ, Brazil); ARTI100 - 4\% articaine with 1:100,000 epinephrine (Articaine 100; DFL); and ARTI200 - 4\% articaine with 1:200,000 epinephrine (Articaine 200; DFL). The dose used was $1.8 \mathrm{~mL}$ (equivalent to 1 cartridge) of anesthetic solution.

Three cartridges of each local anesthetic solution were sealed in 30 envelopes (one for each patient). During application, the main investigator who administered the three injections (one per appointment) randomly removed one cartridge from the envelope. Only one cartridge was randomly chosen and administered per appointment. The initial tooth to be restored was randomly selected. Restorative procedures were conducted during three ¿ appointments, one per clinical session. In addition, pulp vitality was tested in the teeth to be restored, those adjacent, and contralateral canines. These tests were conducted by a blinded researcher to ensure that the the double-blindness of the study. There was a 1-week interval between appointments.

The electric test on the contralateral canine, conducted without anesthesia, was used to ensure that the device was working properly and that subjects were responding correctly. To test pulp vitality, an electric pulp stimulator Vitality Scanner Model 2006 ("pulp tester") (SybronEndo, Orange, CA, USA) was used, which automatically starts measuring as soon as contact is established between teeth and probe tip. Conductive gel to electrocardiogram and ultrasound was applied at the vestibular surface of the medium interface of the tooth crown (Med Systems; Flexor Ltd., Sertãozinho, SP, Brazil) to facilitate conduction between tooth and the tip of the apparatus. As a criterion to determine establishment of pulpal anesthesia, two consecutive negative responses were used to stimulate the apparatus' maximum ( $80 \mu \mathrm{a})$.

Injections were administered using a side-loading Carpule syringe, fifed with a 27 gauge $0.4 \times 35 \mathrm{~mm}$ needle (Teruno Dental Needle; DFL). The injection technique was conducted as previously described (15): blood aspiration tests were carried out before anesthesia injection as well as when changing needle position. In the first step of the anesthesia the needle was introduced 3-5 $\mathrm{mm}$ deep, the blood was aspirated, and approximately $0.3 \mathrm{~mL}$ anesthetic solution was injected. In the second step, the syringe was directed to the premolar region of the opposite side, where the needle was inserted until establishing bone contact. Thereafter, the needle was withdrawn 1-2 $\mathrm{mm}$, the blood was aspirated, and the remaining $1.5 \mathrm{~mL}$ of anesthetic solution was slowly injected. The average injection time was approximately 2 min.

Pulp vitality was tested in restored teeth, adjacent teeth and contralateral canines, $10 \mathrm{~min}$ before administering anesthesia, twice in succession, to obtain baseline mean values. After anesthetic injection, pulp vitality was tested in the respective teeth during the first minute and then again at 60-s intervals until anesthesia was confirmed (determining pulpal anesthesia onset period). After confirming anesthesia, the tests were conducted every 3 min until tooth sensitivity returned, not necessarily required to attain baseline values (determining pulpal anesthesia duration period).

Repeated-measures analysis of variance was used to compare the mean pulpal anesthesia onset and duration for the three local anesthetic solutions. Tukey's test was applied to locate differences between means. Significance level was set at 0.05 . All analyses were conducted using the SPSS software (SPSS Inc., Chicago, IL, USA).

\section{Results}

The means and standard deviations of onset and duration of pulpal anesthesia period samples were plotted in Figures 1 and 2, respectively.

The mean onset of pulpal anesthesia for LID0100, ARTI100 and ARTI200 was 8.7 (S.D., $3.1 \mathrm{~min}$ ), 7.4 (S.D.,

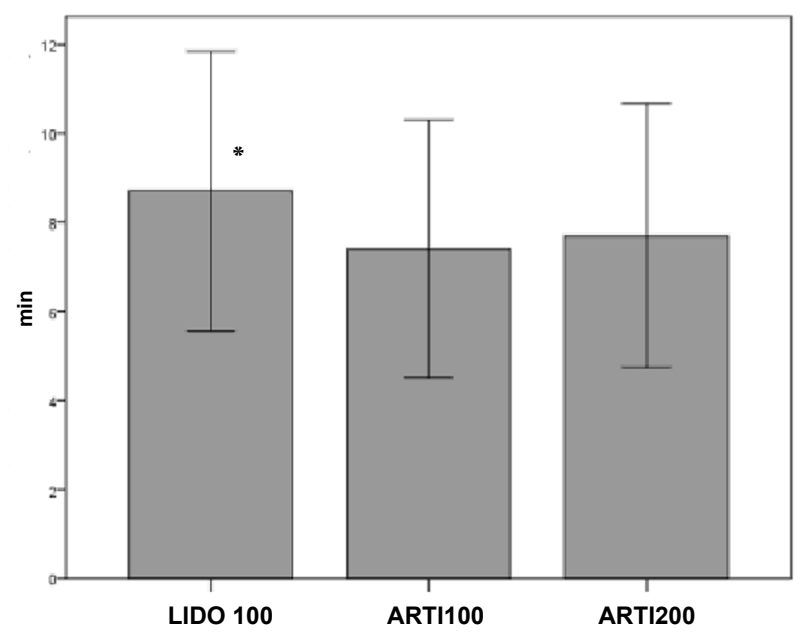

Figure 1. Mean onset of pulpal anesthesia in min (and standard deviation) for $2 \%$ lidocaine with 1:100,000 epinephrine (LID0100), 4\% articaine with 1:100,00 epinephrine (ART1100), and 4\% articanie with 1:200,000 epinephrine (ART1200) after 1ANB. The asterisks indicate statistically significant different at $p<0.05$. 
$2.9 \mathrm{~min}$ ) and 7.7 (S.D., $3.0 \mathrm{~min}$ ), respectively (Fig. 1). There was only a significant difference between ARTI100 and LID0100 ( $p=0.037)$.

The mean duration of pulpal anesthesia for LID0100, ARTI100 and ARTI200 was 61.8 (S.D, $15.5 \mathrm{~min}$ ), 106.6 (S.D., $28.4 \mathrm{~min}$ ) and 88.0 (S.D., $28.9 \mathrm{~min}$ ), respectively (Fig. 2). There was significant difference for all the local anesthetic solutions $(p \leq 0.05)$.

\section{Discussion}

To evaluate the onset and duration pulpal anesthesia of anesthetic solutions could be used to the visual analogic scale $(1,13)$ and electric pulp testing $(16)$. Electric test is an used method to evaluate of standardized way onset and duration pulpal anesthesia $(21,22)$. However, according to Colley et al. (23) there are some limitations: may be the false-positive responses, which can also be involved with the complex mechanism of neuroinflammatory and neuropulpal interactions (nerveodontoblast interactions), which still need to be clarified (24). There are suppositions to relate the type of intrapulpal sensory nerve fibers (A-delta and $A$-beta myelinated fibers and unmyelinated $C$ fibers) to clinical pulp testing methods (25). (A-delta fibers are those stimulated in electric pulp testing because of their distribution, larger diameter than that of $C$ fibers, their conduction speed, and their myelin sheath, whereas $C$ fibers do not respond to electric pulp testing because of their high threshold; therefore, a stronger electric current is needed to stimulate them).

There are several studies assessing onset and duration periods of articaine, but they used different methodologies that hinder direct comparisons with our results $(1,6,7,13,17)$.

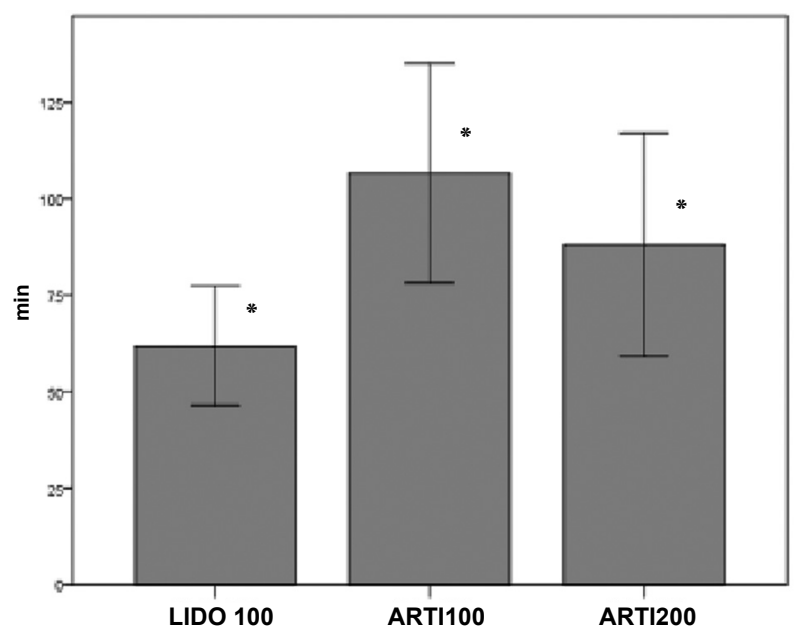

Figure 2. Mean duration of pulpal anesthesia in min (and standard deviation) for the 2\% lidocaine with 1:100,000 epinephrine (LID0100), 4\% articaine with epinephrine 1:100,000 (ART1100), and 4\% articaine with 1:200,000 epinephrine (ART1200) after IANB. The asterisks indicate statistically significant different at $p<0.05$ ).
Some studies have assessed these parameters in maxillary infiltration $(7,17)$ while others, although assessing onset in IANB, did not use an electric pulp stimulator $(1,13)$. A few studies investigated articaine in IANB using an electric pulp stimulator to measure pulpal anesthesia onset and duration periods $(21,22)$ the same methodology applied in our work. However, these authors $(21,22)$ compared articaine solutions containing epinephrine $(1: 100,000$ and $1: 200,000)$, but not with lidocaine solution containing epinephrine $(1: 100,00)$.

The results of the present study indicate that pulp onset periods, 7.4 and $7.7 \mathrm{~min}$, for the two articaine solutions were not influenced by different epinephrine concentrations, $1: 100,000$ and $1: 200,000$, respectively. Our onset values of pulpal anesthesia were higher than those found by Moore et al. (22) (4.2 and $4.7 \mathrm{~min}$ ) and close to those found by Tofoli et al. (21) (7.0 and $8.0 \mathrm{~min}$ ) with epinephrine concentrations of 1:100,000 and 1:200,000, respectively. In both studies $(21,22)$, no statistically significant differences were found between onset values of pulpal anesthesia for both articaine solutions with different epinephrine concentrations, which corroborates our results.

The relationship of epinephrine concentration with onset and duration periods of pulpal anesthesia in IANB is poorly documented. We found only one study in which the authors used lidocaine with epinephrine concentrations of $1: 50,000$ and $1: 100,000$ by using the IANB.

The lowest duration of pulpal anesthesia observed in the present study was for LID0100 $(61.8 \pm 15.5 \mathrm{~min})$, which was significantly lower than for both articaine solutions, ARTI200 (88.0 $\pm 28.9 \mathrm{~min})(\mathrm{p}<0.001)$ and ARTI100 (106.6 $\pm 28.4 \mathrm{~min})(\mathrm{p}<0.001)$.

We found statistically significant difference in pulpal anesthesia duration between the two articaine solutions, where the mean time for ARTI100 (106.6 min) was statistically higher than for ARTI200 (88.0 min) $(p<0.001)$, therefore epinephrine concentration affected duration period in articaine solutions. Our pulpal anesthesia duration values were higher than those found by Tofoli et al. (21) (66 and $61 \mathrm{~min}$ ) and Moore et al. (22) (61.8 and $51.2 \mathrm{~min}$ ) for epinephrine concentrations of 1:100,000 and 1:200,000, respectively. Values found by Tofoli et al. (21) and Moore et al. (22) did not exhibit statistically significant difference in pulpal anesthesia duration between articaine solutions, contrasting with our results.

The results obtained in this study support articaine's superiority over lidocaine in onset period of pulpal anesthesia in IANB when both contain the same epinephrine concentration $(1: 100,000)$. However, further studies are needed to assess whether higher epinephrine concentration $(1: 100,000)$ in the lidocaine solution improves its onset to the same point as the articaine solution with lower epinephrine concentration $(1: 200,000)$, as observed in the 
obtained results.

In conclusion, 4\% articaine with 1:100,000 epinephrine exhibited faster onset and also had longest duration of pulpal anesthesia when compared with all solutions.

\section{Resumo}

A proposta deste estudo prospectivo, randomizado e duplo cego foi comparar o periodo de latência e duração da anestesia pulpar utilizando lidocaina 2\% com epinefrina 1:100.000, articaina 4\% com epinefrina 1:100.000 e articaina 4\% com epinefrina 1:200.000 no bloqueio do nervo alveolar inferior (BNAI). Trinta pacientes receberam 1,8 $\mathrm{mL}$ de cada uma das soluções anestésicas no BNAI. Os periodos de latência e duração da anestesia pulpar foram determinados usando estimulação pulpar elétrica. 0 tempo médio da latência da anestesia pulpar foi 8,7, 7,4 e 7,7 min e da duração média da anestesia pulpar foi 61,8, 106,6 e 88,0 min para lidocaina $2 \%$ com epinefrina 1:100.000, articaina $4 \%$ com epinefrina 1:100.000 e articaina 4\% com epinefrina 1:200.000, respectivamente. Para latência houve somente diferença significante entre lidocaina $2 \%$ com epinefrina 1:100.000 e articaina 4\% com epinefrina 1:100.000 ( $p=0,037)$. Para a duração houve diferença significante para todas as soluções anestésicas locais $(p \leq 0,05)$. Em conclusão, articaina 4\% com epinefrina 1:100.000 exibiu mais rápida latência e também obteve mais longa duração da anestesia pulpar no BNAI.

\section{References}

1. Malamed SF, Gagnon S, Leblanc D. Efficacy of articaine: a new amide local anesthetic. J Am Dent Assoc 2000;131:635-642.

2. Schertzer Jr ER. Articaine vs. lidocaine (comment). J Am Dent Assoc 2000;131:1238-1244.

3. Kanaa MD, Withworth JM, Corbett IP, Meechan JG. Articaine and lidocaine mandibular buccal infiltration anesthesia: a prospective randomized doubleblind cross-over study. J Endod 2006;32:296-298.

4. Robertson D, Nusstein J, Reader A, Beck M, McCartney M. The anesthetic efficacy of articaine in buccal infiltration of mandibular posterior teeth. J Am Dent Assoc 2007;138:1104-1112.

5. Haase A, Reader A, Nusstein J, Beck M, Drum M. Comparing anesthetic efficacy of articaine versus lidocaine as a supplemental buccal infiltration of the mandibular first molar after an inferior alveolar nerve block. J Am Dent Assoc 2008;139:1228-1235.

6. Jaber A, Whitworth JM, Corbet IP, AI-Baqshi B, Kanaa MD, Meechan JG. The efficacy of infiltration anaesthesia for adult mandibular incisors: a randomized double-blind cross-over trial comparing articaine and lidocaine buccal and buccal plus lingual infiltrations. Br Dent J 2010;209:1-6.

7. Costa CG, Tortamano IP, Rocha RG, Francischone CE, Tortamano N. Onset and duration periods of articaine and lidocaine on maxillary infiltration. Quint Int 2005;36:197-201.

8. Srinivasan N, Kavitha M, Loganathan CS, Padmini G. Comparison of anesthetic efficacy of $4 \%$ articaine and $2 \%$ lidocaine for maxillary buccal infiltration in patients with irreversible pulpitis. Oral Surg Oral Med Oral Pathol Oral Radiol Endod 2009;107:133-136.
9. Malamed SF, Gagnon S, Leblanc D. Articaine hydrochloride: a study of the safety of a new amide local anesthetic. J Am Dent Assoc 2001;132:177-185.

10. Claffey E, Reader A, Nusstein J, Beck M, Weaver J. Anesthetic efficacy of articaine for inferior alveolar nerve blocks in patients with irreversible pulpitis. J Endod 2004;30:568-571.

11. Berlin J, Nusstein J, Reader A, Beck M, Weaver J. Efficacy of articaine and lidocaine in a primary intraligamentary injection administered with a computer controlled local anesthetic delivery system. Oral Surg Oral Med Oral Pathol Oral Radiol Endod 2005;99:361-366.

12. Mikesell P, Nusstein J, Reader A, Beck M, Weaver J. A comparison of articaine and lidocaine for inferior alveolar nerve blocks. J Endod 2005;31:265-270.

13. Sierra Rebolledo A, Delgado Molina E, Berini Aytis L, Gay Escoda C. Comparative study of the anesthetic efficacy of $4 \%$ articaine versus $2 \%$ lidocaine in inferior alveolar nerve block during surgical extraction of impacted lower third molars. Med Oral Patol Oral Cir Bucal 2007;12:E139-E144.

14. Sherman MG, Flax M, Namerow K, Murray PE. Anesthetic efficacy of the Gow-Gates injection and maxillary infiltration with articaine and lidocaine for irreversible pulpitis. J Endod 2008;34:656-659.

15. Tortamano IP, Siviero M, Costa CG, Buscariolo IA, Armonia PL. A comparison of the anesthetic efficacy of articaine and lidocaine in patients with irreversible pulpitis. J Endod 2009;35:165-168.

16. Corbett IP, Kanaa MD, Whitworth JM, Meechan JG. Articaine infiltration for anesthesia of mandibular first molars. J Endod 2008;34:514-518.

17. Kannaa MD, Whitworth JM, Meechan JG. A comparison of the efficacy of $4 \%$ articaine with 1:100,000 epinephrine and 2\% lidocaine with $1: 80.000$ epinephrine in achieving pulpal anesthesia in maxillary teeth with irreversible pulpitis. J Endod 2012;38:279-282.

18. Katyal V. The efficacy and safety of articaine versus lignocaine in dental treatments: a meta-analysis. J Dent 2010;38:307-317.

19. Meechan J. Articaine and lignocaine. Evid-Bas Dent 2011;12:21-22.

20. Brandt RG, Anderson PF, McDonald NJ, Sohn W, Peters MC. The pulpal anesthetic efficacy of articaine versus lidocaine in dentistry. A metaanalysis. J Am Dent Assoc 2011;142:493-504.

21. Tofoli GR, Ramacciato JC, Oliveira PC, Volpato MC, Groppo FC, Ranali J. Comparison of effectiveness of 4\% articaine associated with 1:100,000 or 1:200,000 epinephrine in inferior alveolar nerve block. Anesth Prog 2003;50:164-168.

22. Moore PA, Boynes SG, Hersh EV, DeRossi SS, Sollecito TP, Goodson $J M$, et al.. The anesthetic efficacy of 4 percent articaine 1:200,000 epinephrine: two controlled clinical trials. Am Dent Assoc 2006;137:1572-1581.

23. Cooley RL, Stilley J, Lubow RM. Evaluation of a digital pulptester. Oral Surg 1984;58: 437-442.

24. Sampaio RM, Carnaval TG, Lanfredi CB, Horliana ACRT, Rocha RG, Tortamano IP. Comparison of the anesthetic efficacy between bupivacaine and lidocaine in patients with irreversible pulpitis of mandibular molar. J Endod 2012;38:594-597.

25. Abd-Elmeguid A, Yu DC. Dental pulp neurophysiology: part 1. Clinical and diagnostic implications. CDA J 2009;75:55-59.

Received October 16, 2012 Accepted July 25, 2013 